\title{
EVALUATION OF EPIDEMIOLOGICAL AND CLINICAL CHARACTERISTICS AND SELF EVALUATION OF DISEASE OF PATIENTS WITH SYSTEMIC SCLEROSIS IN AN OUTPATIENT RHEUMATOLOGIC CLINIC OF PERNAMBUCO
}

Hugo Deleon de Lima ${ }^{1}$, Pedro Arturo Bismara Carneiro Santos ${ }^{1}$, Rafael da Rocha Caminha ${ }^{1}$, Mirella Patrício Rodrigues ${ }^{1}$, Thiago Henrique da Silva Rached ${ }^{1}$, lanny Cristiny Rafael Diniz ${ }^{1}$, Tulio Silva Freire ${ }^{1}$, Laurindo Ferreira da Rocha Junior ${ }^{1, *}$

1.Instituto de Medicina Integral Professor Fernando Figueria, Recife (BA), Brazil.

*Corresponding author: laurindorochajr@hotmail.com

\section{BACKGROUND}

Systemic sclerosis (SSC) is a rare autoimmune disease characterized by vasculopathy, inflammation, collagen deposition and fibrosis of the skin and internal organs and is considered the most severe connective tissue disorder with a high morbimortality. The present study aimed to analyze characteristics of patients diagnosed with SSc assisted at tertiary hospital in the state of Pernambuco.

\section{METHODS}

A descriptive cross-sectional study with an analytical component was carried out with $22 \mathrm{SSc}$ patients. Patients included fulfilled classification criteria for SSc. Clinical, epidemiological and laboratorial data were collected by clinical assessment, interview and review of hospital records. Statistical analysis was performed using GraphPad Prim software v.6.0.

\section{RESULTS}

The majority of the patients were female ( $n=18,82 \%)$. The mean age of the patients was 46.5 years ( \pm 11.67$)$. Fourteen patients $(64 \%)$ had 5 or more years of diagnosis. Seventeen (77\%) patients had the diffuse cutaneous form. The most frequent comorbidity was hypertension ( $n=7,32 \%$ ). Raynaud's phenomenon was part of clinical feature of SSc in 18 (82\%) patients, and 15 patients $(68 \%)$ had esophagus dysmotility. Elderly patients $(n=4)$ had less painful joints $(p=0.02)$, minor values of Borg dyspnea score ( $p=0.0167)$, scores of patient evaluation of visual analogue scales (VAS) for gastrointestinal symptoms $(p=0.007)$ and global evaluation of disease $(p=0.034)$. Patients with dyspnea $(n=13)$ had significant associations with worse clinical parameters such as Raynaud's phenomenon $(p=0.04)$ and gastrointestinal symptoms $(p=0.0062)$. There was negative significant correlation between VAS score evaluation of global disease and age $(r=-0.5748, p=0.0051)$. Scores for global disease evaluation of the patients correlated significantly with VAS patients scores of Raynaud phenomenon $(p<0.0001)$, gastrointestinal symptoms $(p=0.0104)$ and dyspnea $(p=0.0002)$.

\section{CONCLUSION}

Patient evaluation of either disease or symptoms was associated with clinical features of systemic sclerosis. Elderly patients have some better parameters of disease. Disease patient complaints should be valued during patients' consultations.

\section{KEYWORDS}

Systemic sclerosis, Dyspnea, Symptoms. 